\title{
EMPIRICAL EVIDENCE OF THE EFFICIENCY AND EFFICACY OF FAT TAXES AND THIN SUBSIDIES
}

\author{
J. Stephen Clark', Ludwig O. Dittrich ${ }^{2}$, Qin $\mathrm{Xu}^{3}$ \\ 'Dalhousie University, Halifax, Canada \\ ${ }^{2}$ Czech University of Life Sciences, Prague, Czech Republic \\ ${ }^{3}$ University of Guelph, Guelph, Canada
}

\begin{abstract}
SUMMARY
This study summarizes the empirical literature on fat taxes and thin subsidies to assess their efficiency and efficacy as instruments of public policy to control obesity. Three specific types of taxes are studied in the literature: food group taxes; nutrient taxes; and nutrient index taxes. A number of studies use food expenditure data to assess the impact of various taxes on obesity and therefore only indirectly measure the impacts of taxes and subsidies on obesity. These studies generally conclude that food group taxes, nutrient taxes and nutrient index taxes have a small impact on the purchases of food and the nutrients purchased. Other studies use the body mass index as the explanatory variable and thus measure the impacts of taxes on body mass index directly. Nutrient taxes are found to be more effective than food group taxes, although even for nutrient taxes, the effects are small. In general, thin subsidies seem to offer more effective control of obesity than obesity taxes. However, due to the small effects of both fat taxes and thin subsidies, they are not recommended as instruments of food and nutrition policy.
\end{abstract}

Key words: fat taxes, thin subsidies, obesity policy, body mass index, consumer expenditure

Address for correspondence: L. O. Dittrich, P.O. Box 10, 16012 Prague 612, Czech Republic. E-mail: dittrich@pef.czu.cz

\section{INTRODUCTION}

Obesity is a growing health problem, especially in the developed world. With the improvement in living standards around the world, people consume more food and do less physical work. According to the Nation Master (1), in 2012, the top ten countries ranked by the percentage of population who were obese included: 1$)$ the US (30.6\%); 2) Mexico (24.2\%); the UK (23\%); Slovakia (22.4\%); Greece (21.9\%); Australia (21.7\%); New Zealand (20.9\%); Hungary (18.8\%); Luxembourg (18.45\%); and the Czech Republic (14.8\%). Hence, obesity is a serious health issue, especially in the developed world.

This increasing trend of obesity prevalence is troubling because obesity is associated with elevated health risks. It could result in adverse metabolic effects on blood pressure, cholesterol, triglycerides and insulin resistance, and it could also lead to respiratory difficulties, chronic musculoskeletal problems and infertility. Moreover, it could cause more serious life threatening problems, such as cardiovascular disease problems, problems associated with insulin resistance such as type 2 diabetes, certain types of cancer, especially the hormonally related and large-bowel cancers, and gallbladder disease, e.g. Smed et al. (2).

Rising obesity rates have led to calls for "fat taxes" and "thin subsidies" as a method to control obesity. While in the abstract the idea of fat taxes or thin subsidies may have a certain appeal, they are difficult to implement in practice. Fundamental to the problem of fat taxes or thin subsidies is a question of what exactly should be taxed or subsidized to control obesity. For example, fat is rather ubiquitous in the food system as the vast majority of foods contain at least some fat. Also, since the objective of fat taxes is to control obesity, it is not clear whether one should target the fat, sugar or calories in food when one is thinking about implementing fat tax. Therefore, for these kinds of taxes and subsidies the "devil is in the details".

Clark and Dittrich (3) discuss the theoretical problems of imposing three different kinds of fat taxes: 1) food group tax (FGT) (which they call a composite commodity tax), a food group tax would impose the same tax rate across a particular food group (e.g. dairy) because it is perceived to have a high fat content. However, the category itself has several different subcategories (e.g. milk and ice cream) that can have large differences in fat content; 2) nutrient tax (NT), a nutrient tax would impose a tax on the nutrient content of food (e.g. grams of fat) regardless of food group; and 3) nutrient index tax (NIT), a nutrient index tax is similar to the nutrient tax with the difference being that a weighted average of nutrients (e.g. grams of fat and carbohydrates) is taxed rather than individual nutrients. They conclude that the efficiency and efficacy of these taxes is highly questionable and recommend that before their implementation empirical estimates need to be derived. This study summarizes the literature on empirical estimates of fat taxes and makes recommendations based on these empirical findings.

Empirical studies that estimate the impact of various kinds of fat taxes can conveniently be categorized into two groups: those that analyze the impact of fat taxes using consumer expenditure data and those that analyze the fat taxes using body mass index (BMI) data. These will be presented in turn. 


\section{MATERIALS AND METHODS}

\section{Empirical Evidence from Studies Using Food Ex- penditure Data}

FGTs, NTs and NITs have been analyzed using food expenditure data, sometimes within the same study. Empirical studies on FGT derive estimates of the elasticity in question from food expenditure data combined with nutrient data in food demand systems (food groups being, for example, fruits and vegetables, dairy, meats). From a nutrition perspective, these food groups also tend to roughly line up to food pyramid groups. Food groups are not necessarily those targeted by advocates of fat taxes to control obesity. For example, advocates of fat taxes often target fast foods or junk food for taxing. Chouinard et al. (4) consider a fat tax on dairy products and it is difficult to conceive that dairy products properly fall in the category of junk food or fast food. Smed et al. (2) include butter, margarine, beef, pork, poultry, sugar, and fruits and vegetables in their study. $\mathrm{Xu}(5)$ includes cereals and bakery products, meats, eggs, fresh fruits and vegetables, sugar and other sweets, fats and oils, and dairy products in her study, whereas Clark and Levedahl (6) include only beef, pork and poultry in theirs. Allais et al. (7) consider 22 food groups. How well these food groups translate into the types of food groups often targeted for taxing (e.g. junk food) is an unanswered question that may limit the usefulness of the results.

Chouinard et al. (4), Smed et al. (2) and Allais et al. (7) combine food demand elasticity of food groups with the average nutrient content of the food group to estimate consumer responses to changes in prices for the US, Danish and French populations, respectively. These authors assume fixed proportions between the overall food group and nutrients. This assumption implies that consumers only substitute nutrients by switching among food groups when price and incomes change, but not within the food groups. For example, substitution of fat between dairy and fruits and vegetables is considered when prices and income change, but substitution between milk and ice cream, is not.

Another problem with the studies by Chouinard et al. (4) and Smed et al. (2) is that the data used to estimate the demand elasticity are based on a food at home data. This means that a large category of food expenditure data (food away from home) is not considered. This means, for example, that a tax on fast food cannot be considered.

Chouinard et al. (4) studied FGT on dairy products and concluded that, since the elasticity of dairy fat with respect to the food group dairy price is small, FGT on dairy product would not be effective in controlling obesity. In a more comprehensive study of French populations, Allais et al. (7) apply FGT to prepared meals, cheese/butter/cream and sugar-fat products. Their data is broken down into four socio-economic classes. They found that the effect of FGT is small, since the nutrient elasticity is inelastic (less than one in absolute value). Other studies that use a similar approach to Allais et al. (7) and find small nutrient elasticity (and therefore small effects of FGTs) include Beatty and LaFrance (8) and Huang (9). The studies by Smed et al. (2) and Allais et al. (7) on the use of FGTs also conclude that, while own price effects may be effective in reducing fat intake, cross price effects may work in the opposite direction. The importance of cross price effects has also been stressed by Schroeter et al. (10) and Mytton et al. (11).
The data used by Smed et al. (2) is stratified by age categories as well as food groups and nutrient categories. They combine nutritional content tables with elasticity estimates to examine FGTs and thin subsidies. They conclude that fat taxes result in a decrease in fat consumed by younger Danes and older Danes, with the largest decrease in fat consumed by younger Danes.

Smed et al. (2) also study NTs. One advantage of the fixed proportion assumption is that both FGTs and NTs can be analyzed together with existing data. Smed et al. (2) also consider a weighting scheme for the nutrients such as sugar, fats and fiber to help mitigate the problem of substitution among the nutrients when only one is taxed. These types of taxes are similar to the nutrient index taxes favoured by Clark and Dittrich (3). They conclude that it is better to impose a weighting scheme on various nutrients in taxing nutrients rather than to impose taxes on individual nutrients.

The accuracy of the results using food at home data depends on the accuracy of three maintained hypotheses:

- the accuracy of the fixed proportions assumption;

- the accuracy of the assumption that the food at home response of consumer expenditures and nutrients when prices change is the same as the "away from home" food response when prices change;

- the accuracy of the assumption that changes in consumer expenditures translate into changes in body mass.

The studies by $\mathrm{Xu}$ (5), and Clark and Levedahl (6) allow for variable proportions between the food groups taxed and their nutrient content. They justify variable proportions by noting that consumers have considerable opportunity to substitute fat and other nutrients within the food group when prices and incomes change so that within the group substitutions are important and need to be accounted for in the analysis. Given the aggregate nature of the food groups, it seems somewhat arbitrary to assume that consumers substitute nutrient intake across groups when prices change due to taxes and subsidies but do not adjust nutrient intake within the food group.

With variable proportions, nutrient price and income elasticity are estimated directly and not tied to the overall food group elasticity, and the negative relationship between own price of the composite and the nutrient is no longer required to hold (3). In this case, FGT would be counterproductive.

Clark and Levedahl (6) and $\mathrm{Xu}(5)$ combine time series data on food groups collected from the Center for Nutrition and Public Policy (CNPP) - per capita nutrient intake with price and income data collected from the Bureau of Labour Statistics (BLS) to estimate price and income elasticity of nutrients. The CNPP data are based on estimates of food availability (production + imports - exports) and then translated into nutrient content by the average nutrient content of the food group (12). Since the CNPP data are based on food availability, they measure both food away from home and food at home per capita nutrient intake. However, the BLS data are based on food at home prices and per capita income. Therefore, these two studies only partly overcome the food at home problem of the Chouinard et al. (4), and Smed et al. (2).

Clark and Levedahl (6) estimate price and income fat content elasticity for the meats: beef with an own price elasticity of 0.014 , statistically insignificant; pork with an own price elasticity of 0.159 , statistically significant; and poultry with an own price elasticity of 0.026 , statistically insignificant. Since all elasticities are positive, they conclude that FGT on any of these meats will be 
counterproductive. $\mathrm{Xu}$ (5) estimates a system of fat, carbohydrate and calorie elasticities of composite food groups. Own price and income elasticity estimated by $\mathrm{Xu}$ (5) are presented in Table 1. It is clear that the own price elasticity of nutrient response to FGT on a food group is not necessarily negative. With a positive own price nutrient elasticity, FGT would be counterproductive. Furthermore, many of the elasticities are statistically insignificant, meaning that the elasticity is zero. A zero own price elasticity implies that consumers adjust to price changes of food group by adjusting the nutritional content within the composite in a way to hold the nutrient content constant, rendering FGT ineffective. Note that verification of the fixed proportions assumption used by Smed et al. (2) would imply that all own price coefficients are negative and statistically significant. Lack of statistical significance in Table 1 therefore does not verify the fixed proportions assumption.

While the Clark and Levedahl (6) study and the Xu (5) study allow for variable proportions and the data at least partly include both food at home and food away from home categories, they only examine the impact of FGTs and not NTs. They also suffer from the fact that they are based on food groups roughly related to the food pyramid not the food groups targeted by advocates of fat taxes.

A problem with food expenditure data and food availability data relates to the problem of how well data on purchases and food availability translate to what consumers actually eat; just because consumers purchase food, it does not mean they eat it. Predicted responses of consumer demand using expenditure data tells us how expenditures may change when prices change, but they do not necessarily tell us what actually enters people's stomach. Some examples of this problem include: purchasers of high fat meat may simply cut away the fat and discard it without eating; barbequing may result in the loss of meat fat; the nutrients in fresh fruits and vegetables purchased by consumers may be lost due to waste and spoilage; the nutrient content of a fruit or vegetable depends on whether it is eaten raw or cooked. Encouraging consumers to eat fresh fruits and vegetables through thin subsidies may have little effect if a large amount of this extra purchase is discarded due to spoilage. This means that there may not be fixed relationship between the nutritional content of food that consumers purchase and the nutritional content of food actually eaten. Furthermore, these effects are not constant across food groups and depend on how these food groups are combined to form meals. These effects would lead one to conclude that studies using consumer expenditure data would overestimate (in absolute value) the effect of taxes and subsidies on obesity.

\section{Empirical Evidence Using Body Mass Index (BMI)}

A number of manuscripts use BMI to study the impact of taxes and subsidies on obesity. An advantage of using BMI data is that these data are more often available, by age, gender and other socio-economic variables than are the food expenditure data. Therefore, the effect of taxes on sub-populations (e.g. children) can be studied.

There are several studies that link prices and other socioeconomic variables with the BMI of populations. Both FGT's and NT's can be studied, depending on the price included. Results of studies using BMI as the regressand are presented in Table 2.

Studies by Chou et al. (13), Auld and Powell (14) and Sturm and Datar (15) include prices that could be used to determine the impact of FGT's. The study by Goldman et al. (16) and Clark et al. (17) include prices of nutrients and could therefore be used to study the impact of NTs. Chou et al. (13) study the impact on the BMI of US adults of the price of food in full service restaurants (in facility dining plus fast food), price food of fast food restaurants only, the price of food in in-facility dining restaurants only, and price of food at home. They find that price food of fast food restaurants and the price of food in in-facility dining only restaurants to be negatively correlated with the BMI of US adults. The prices of fast food restaurants are statistically insignificant. The price of food in full service restaurants and food at home are both positively related to US adult BMI and statistically significant.

Table 1. Own price and income elasticity for calories, fat and carbohydrates

\begin{tabular}{|c|c|c|c|c|c|c|c|}
\hline \multirow[b]{2}{*}{ Variable } & \multicolumn{7}{|c|}{ Food category } \\
\hline & $\begin{array}{l}\text { Cereals and } \\
\text { bakery } \\
\text { products }\end{array}$ & $\begin{array}{l}\text { Meats, poultry, } \\
\text { and fish }\end{array}$ & Eggs & $\begin{array}{l}\text { Fresh fruits and } \\
\text { vegetable }\end{array}$ & $\begin{array}{l}\text { Sugar and other } \\
\text { sweets }\end{array}$ & Fats and oils & Dairy products \\
\hline \multirow{2}{*}{$\begin{array}{l}\text { Calorie versus } \\
\text { Price }\end{array}$} & $0.668^{* *}$ & 0.236 & -0.062 & -0.255 & -0.110 & -0.170 & $-0.371^{*}$ \\
\hline & $(3.41)$ & $(1.02)$ & $(-0.72)$ & $(-1.24)$ & $(-0.35)$ & $(-0.19)$ & $(-2.12)$ \\
\hline \multirow{2}{*}{$\begin{array}{l}\text { Calorie versus } \\
\text { Income }\end{array}$} & $0.638^{* *}$ & 0.236 & -0.553 & 0.039 & 0.211 & $-1.646^{* *}$ & 0.342 \\
\hline & $(3.54)$ & $(1.02)$ & $(-1.58)$ & $(0.15)$ & $(1.27)$ & $(-2.38)$ & $(1.65)$ \\
\hline \multirow{2}{*}{ Fat versus Price } & $1.847^{\star *}$ & 0.509 & -0.041 & -0.946 & \multirow{2}{*}{ NA } & -0.329 & -0.397 \\
\hline & (5.33) & $(1.72)$ & $(-0.69)$ & $(-0.96)$ & & $(-0.38)$ & $(-1.42)$ \\
\hline \multirow{2}{*}{$\begin{array}{l}\text { Fat versus } \\
\text { Income }\end{array}$} & $0.941^{* *}$ & -0.253 & $-0.869^{* *}$ & $-3.761^{* *}$ & \multirow{2}{*}{ NA } & $-1.763^{\star *}$ & 0.469 \\
\hline & $(2.95)$ & $(-0.58)$ & $(-3.59)$ & $(-2.99)$ & & $(-2.66)$ & (1.41) \\
\hline \multirow{2}{*}{$\begin{array}{l}\text { Carbohydrate } \\
\text { versus Price }\end{array}$} & $0.899^{* *}$ & $-0.308^{* *}$ & -0.027 & -0.013 & -0.579 & \multirow{2}{*}{ NA } & -0.176 \\
\hline & $(4.46)$ & $(-3.13)$ & $(-0.76)$ & $(-0.07)$ & $(-1.73)$ & & $(-0.89)$ \\
\hline \multirow{2}{*}{$\begin{array}{l}\text { Carbohydrate } \\
\text { versus Income }\end{array}$} & $0.503^{* *}$ & 0.239 & 0.239 & 0.059 & 0.071 & \multirow{2}{*}{ NA } & 0.115 \\
\hline & $(2.71)$ & $(1.63)$ & (1.63) & $(0.23)$ & $(0.40)$ & & $(0.49)$ \\
\hline
\end{tabular}

The values in brackets are t-value. $\left({ }^{*} p<0.10,{ }^{* *} p<0.05\right)$. NA: the nutrient was zero for these categories. Source: Xu $2011(5)$ 


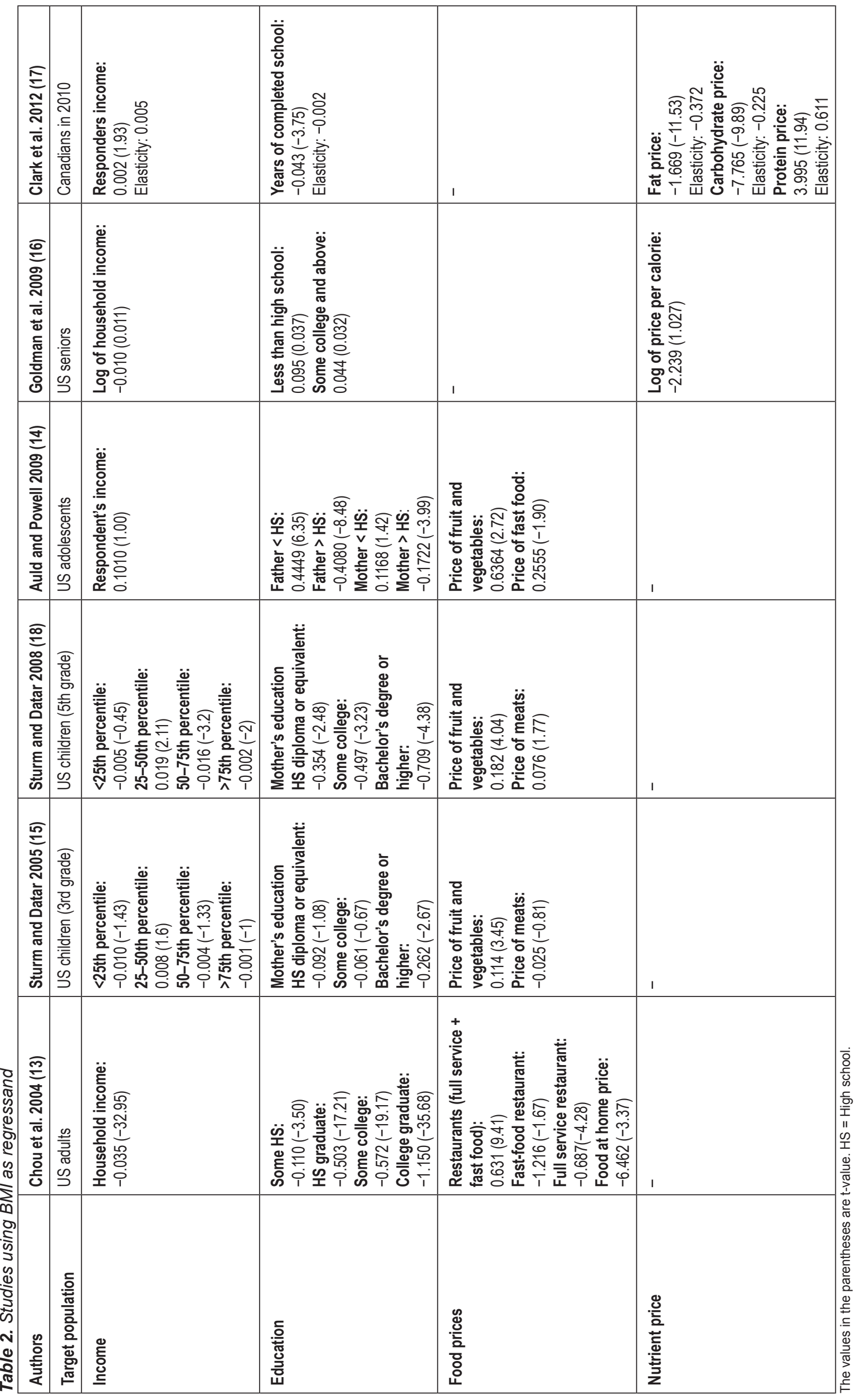


The study by Auld and Powell (14) includes the price of fast food and the price of fruits and vegetables in a study of the BMIs of US teenagers. They find the price of fast food to be negatively related to teenager BMI but statistically insignificant and the price of fruits and vegetables to be positive and statistically significant. Sturm and Datar study the BMI of children less than three years old (15) and children less than 5 years old (18), including the prices of fruits and vegetables and the price of meat. Meat prices are insignificant in both studies whereas the price of fruits and vegetables are positive and statistically significant.

The results of the Chou et al. study (13) and the Auld and Powell study (14) indicate that there is little empirical support for the taxing of fast food as a way to reduce obesity in US populations. The coefficient on the fast food price is negative but statistically insignificant. However, the results of Chou et al. (13) tend to support the notion that thin subsidies applied to the fruits and vegetables food group would have the impact of lowering the BMI of US populations. At present, there is no empirical evidence related to taxing junk food in the empirical BMI literature. This may be because the term itself is vague and because it is difficult to line up junk food to any food group in existing food databases in order to build a meaningful proxy for a junk food price.

Studies by Goldman et al. (16) and Clark et al. (17) include nutrient prices in the specification of the BMI equations. Goldman et al. (16) includes the price of calories and finds that the calorie price is negatively related to the BMI of US adults, but is statistically insignificant. The results of a study by Clark et al. (17) indicate that the estimated coefficients on the price of fat, the price of carbohydrates and the price of protein are all statistically significant. The elasticity of both fat $(-0.372)$ and carbohydrates $(-0.225)$ are small and negative whereas the elasticity of protein price is larger in absolute value and positive (0.611). These results indicate that a nutrient tax on the fat content of food and a nutrient tax on the carbohydrate content of food would reduce the BMI of Canadian adults, as would a thin subsidy on the protein content of food. However, all elasticities are small and therefore would not result in large reductions in the BMI of Canadians. Finally, since Table 2 includes elasticity estimates for different age groups, the results could be used to justify different food taxes for different age groups. However, imposing food taxes on different age groups would seem to be both impractical and politically unfeasible.

The studies of BMI either enter prices of food groups so that FGTs can be assessed or nutrient prices so that NTs can be assessed. In terms of various taxes, there is little support for the notion that taxing fast food will lower BMI, however, there is some support for the notion that taxing sugar and fat may have the desired impact. Subsidies on fruits and vegetables and protein may also help to reduce the BMI of children.

\section{CONCLUSIONS}

The empirical literature on fat taxes and thin subsidies is fairly small but growing. Three types of taxes have been studied: food group taxes (FGTs), nutrient taxes (NTs) and nutrient index tax (NIT). The literature on food group taxes indicates that a tax on fast food may not be an effective tool in controlling obesity. There are no empirical studies that specifically study a tax on junk food, perhaps because the term is so vague that it cannot be approxi- mated in the data. This could be an area for future studies. The literature does provide some evidence that thin subsidies applied to fruits and vegetables may reduce the body mass of children and teenagers. The empirical literature on the effectiveness of nutrient taxes seems to be encouraging; there is some evidence to support the notion that taxing fat and sugar will help reduce the obesity. However, most of the estimated elasticities are small, indicating that the effects of a tax on BMI may be small. There is some evidence that a thin subsidy on protein is more effective tool to reduce BMI given its elasticity is higher than either the fat or sugar elasticity, although it is still inelastic. A nutrient index tax may be more effective than a tax on a single nutrient.

Notwithstanding the impact of demand side nutrient taxes, is the possible supply side response of food producers to taxes. For example, if a tax on the fat content of food is imposed, manufacturers may simply substitute sugar for fat in food to avoid the tax. This may do little to reduce the intake of weight causing nutrients by populations. How suppliers would respond to taxes is an area that is important, but neglected area requiring further research.

Regardless of whether we use expenditure data or BMI data, most studies conclude that the effect of fat taxes and thin subsidies is rather small. These conclusions are invariant to whether food group taxes, nutrient taxes, or nutrient index taxes are considered. This means that these taxes would be expensive, regressive and ineffective. Therefore, they are not recommended. Some other policies could be more effective. They may be public awareness programmes, youth education programmes and others. Economic instruments do not seem to be very effective to reverse the ongoing obesity epidemic.

\section{REFERENCES}

1. Nationmaster. Health. Obesity: countries compared [Internet]. Nationmaster [cited 2013 Jun 13]. Available from: http://www.nationmaster. com/graph/hea obe-health-obesity.

2. Smed S, Jensen JD, Denver S. Socio-economic characteristics and the effect of taxation as a health policy instrument. Food Policy. 2007;32(56):624-39

3. Clark JS, Dittrich OL. Alternative fat taxes to control obesity. Int Adv Econ Res. 2010;16(4):388-94.

4. Chouinard HH., Davis DE, LaFrance JT, Perloff JM. Effects of a fat tax on dairy products. CUDARE working paper, no. 1007. Berkeley: University of California; 2005.

5. Xu Q. Consumers' decisions on calories, fat, and carbohydrates with respect to food prices and expenditures [dissertation]. Halifax: Dalhousie University; 2011.

6. Clark JS, Levedahl JW. Will fat taxes cause Americans to become fatter? Some evidence from US meats. In: 26th Conference of the International Association of Agricultural Economists; 2006 Aug 12-18; Gold Coast, Australia.

7. Allais O, Bertail P, Nichele V. The Effects of a fat tax on French household's purchases: a nutritional approach. Am J Agr Econ. 2010; 92(1):22845.

8. Beatty TKM, LaFrance JT. United States demand for food and nutrients in the twentieth century. Am J Agr Econ. 2005;87(5):1159-66.

9. Huang KS. Nutrient elasticities in a complete food demand system. Am J Agr Econ. 1996;78(1):21-9.

10. Schroeter C, Lusk J, Tyner W. Determining the impact of food price and income changes on body weight. J Health Econ. 2008 Jan;27(1):45-68.

11. Mytton O, Gray A, Rayner M, Rutter H. Could targeted food taxes improve health? J Epidemiol Community Health. 2007 Aug;61(8):689-94.

12. Hiza HAB, Bente L. Nutrient content of the U.S. food supply: developments between 2000 and 2006. Home economics research report, no. 59. Washington: United States Department of Agriculture, Center for Nutrition Policy and Promotion; 2011. 
13. Chou SY, Grossman M, Saffer H. An economic analysis of adult obesity: results from the Behavioral Risk Factor Surveillance System. J Health Econ. 2004 May;23(3):565-87.

14. Auld MC, Powell LM. Economics of food energy density and adolescent body weight. Economica. 2009;76(304):719-40.

15. Sturm R, Datar A. Body mass index in elementary school children, metropolitan area food prices and food outlet density. Public Health. 2005 Dec;119(12):1059-68.

16. Goldman D, Lakdawalla D, Zheng Y. Food prices and the dynamics of body weight. NBER working paper, no. 15096. Cambridge: National Bureau of Economic Research; 2009.
17. Clark JS, Xu Q, Law S. Socioeconomic and health determinants of Canadians' Body Mass Index. Working paper. Department of Business and Social Science, Dalhousie University; 2012.

18. Sturm R, Datar A. Food prices and weight gain during elementary school: 5-year update. Public Health. 2008 Nov;122(11):1140-3.

Received June 19, 2013 Accepted in revised form May 30, 2014 